\title{
Workload, organisation, and cost of haematology laboratory out of hours services
}

\author{
J Shirley, S Wing
}

\begin{abstract}
Background-The cost of out of hours services makes up a considerable proportion of the total laboratory budget and this has encouraged haematologists to examine workload patterns and the organisation and cost of out of hours services. Aim-To review current levels of out of hours workload and examine the organisation and cost of the service in the South Thames region.

Method-Data collection was by questionnaire and data analysis by Microsoft Excel.

Results-A variety of methods of organising and financing out of hours services were identified. There was a large variation in workload between different centres. There has been a rise in total workload and out of hours workload over a three year period. The most common tests to take place outside routine hours are full blood counts and clotting screens. The method of providing out of hours services did not affect total numbers of out of hours tests. There were considerable costs associated with time off in lieu for on call staff.

Conclusions-The variation and increase in out of hours tests is not related to the way that out of hours services are provided, but is more likely to result from changes in medical practice. There are pronounced differences between centres in the numbers of different types of tests performed out of hours, which are not related to the numbers of acute beds. There is no single model of out of hours service provision that suits all situations. (F Clin Pathol 2001;54:647-649)
\end{abstract}

Keywords: haematology; laboratory; out of hours; cost; organisation; workload

South Thames

Haematology Audit

Committee,

Haematology

Department, Royal

Surrey County

Hospital, Egerton

Road, Guildford,

Surrey GU2 5XX, UK

J Shirley

$S$ Wing

Correspondence to:

Dr Shirley

Accepted for publication 2 October 2000 and cost effectiveness, must take into account out of hours services.

In 1996, the South Thames haematologists undertook a regional audit of laboratory out of hours services. The audit aimed to establish workload levels, the type and source of tests performed, on call processes, and the costs associated with providing out of hours services. $^{2}$

The 1996 audit found a large difference in the total number of tests and the number of out of hours tests performed for each acute bed between centres in the South Thames region. However, variations in definitions of a request and a test resulted in difficulties in producing valid comparative data and may have explained the findings.

In 1995/96 the cost of providing haematology out of hours services ranged from $£ 18$ 200/ annum to $£ 230000$ (12.6 fold variation). Out of hours staff payments varied from $8 \%$ to $41 \%$ of the total laboratory staff budget. Taking regional averages in 1995/96, out of hours tests accounted for $12.4 \%$ of the total workload and cost $23.7 \%$ of the budget. In 1999, a follow up study reviewed the laboratory out of hours workload and examined the organisation and cost of the service.

\section{Methods}

Since 1996, many haematology laboratories in the UK have participated in the Clinical Benchmarking Company (CBC Ltd) study of laboratory services, which produces comparative data on the amount, type, and cost of workload, and on staffing arrangements.

As a result of the 1996 study, it was agreed to adopt the CBC's definitions of a request and a test to enable accurate regional comparisons to be made. ${ }^{3}$ During March 1999, one haematologist at each of the 22 centres that participate in the audit study collected data on haematology laboratory workload and the direct costs of providing an out of hours service using a questionnaire. Information was supplied on the organisation and financing of out of hours services, acute bed numbers, and routine weekend hours. Weekday routine hours were defined as 08.00 to 17.00 for all centres.

Data were collated and analysed using Microsoft Excel. Data analysis compared centres by total workload and by workload/ acute bed. Results were presented and discussed at a meeting of the South Thames haematologists, in the presence of Dr M Galloway, Consultant Haematologist, Bishop Auckland Hospital and expert panellist for the CBC. 
Table 1 Haematology laboratory workload in South Thames in 1996 and 1999

\begin{tabular}{|c|c|c|}
\hline & $\begin{array}{l}1996 \text { (average month minus total } \\
1996 \text { workload divided by 12) }\end{array}$ & 1999 (March) \\
\hline Total requests & 260899 & $287736(10 \%$ increase $)$ \\
\hline Range & $2759-25833$ (9 fold) & $1768-27287(15$ fold $)$ \\
\hline $\mathrm{OOH}$ requests & 27067 & 39167 (45\% increase) \\
\hline Range & $74-3833$ (52 fold) & $197-7425(38$ fold $)$ \\
\hline Total tests & 431559 & 621709 (44\% increase) \\
\hline Range & $6072-53185$ (9 fold) & $2705-74523$ (28 fold) \\
\hline Total tests/acute bed & $32.17-109.9$ (3.4 fold $)$ & $33.81-91.76$ (2.7 fold $)$ \\
\hline $\mathrm{OOH}$ tests & 34083 & $71734(110 \%$ increase $)$ \\
\hline Range & $504-3500(7$ fold $)$ & $378-8181(22$ fold $)$ \\
\hline OOH tests/acute bed & $1.67-8.67$ (5.2 fold) & $2.34-16.86(7.2$ fold $)$ \\
\hline $\mathrm{OOH}$ tests/acute admission & N/A & $0.4-3.194(7.9$ fold $)$ \\
\hline
\end{tabular}

$\mathrm{OOH}$, out of hours.

Table 2 Range of out of hours $(\mathrm{OOH})$ tests

\begin{tabular}{llll}
\hline Type of test & $\begin{array}{l}\text { Total OOH tests } \\
\text { (March 1999) }\end{array}$ & $\begin{array}{l}\text { Range of OOH } \\
\text { tests/centre }\end{array}$ & $\begin{array}{l}\text { Range of tests/ acute } \\
\text { bed/centre }\end{array}$ \\
\hline Full blood count & 37779 & $138-6341$ & $0.81-9.32$ \\
Clotting screens & 14173 & $84-2286$ & $0.43-2.55$ \\
Cross match & 4439 & $42-1282$ & $0.08-1.30$ \\
Blood group & 3320 & $14-1098$ & $0.06-1.89$ \\
\hline
\end{tabular}

\section{Results}

ORGANISATION AND FINANCING OF OUT OF HOURS SERVICES

Two centres in South Thames continue with the traditional Whitley Council arrangements. Most haematology departments (82\%) offer staff a fixed sessional payment based on Whitley Council standby and call out rates. In three of these centres a partial shift system is combined with fixed pay on call sessions. Two centres run full shift systems.

Acute bed numbers for hospitals in the South Thames region range from 80 to 1500 . The two hospitals with the least acute beds use Whitley Council on call payments. Partial shift and full shift systems have been selected by five departments based in average or above average sized hospitals.

\section{TOTAL AND OUT OF HOURS HAEMATOLOGY}

LABORATORY WORKLOAD

The adoption of the CBC's definitions of a test and a request did not greatly reduce the variations in workload, which had been identified in 1996 (table 1).

Total requests, out of hours requests, total tests, and out of hours tests have all risen in the three year period between 1996 and 1999 (table 1). The rise in overall workload could be explained by the increase in acute beds throughout the region. The total bed numbers for participating centres in 1996 was 10806 $(\mathrm{n}=27)$ compared with $11627(\mathrm{n}=22)$ in 1999. Acute bed numbers in the 19 centres to take part in both audits rose by $29 \%$ from 7674 to 9934 . Whereas the total tests/acute bed have remained constant the out of hours tests have increased. Analysis by acute bed numbers standardises the data and reduces (but does not eliminate) the variations in practice. Analysis was also carried out by the number of out of hours tests/acute admission for March 1999 and this showed a similar range to analysis by acute bed numbers (7.9 fold variations by acute admission and 7.2 fold by acute bed).

\section{OUT OF HOURS LABORATORY TESTS}

Information was gathered to determine the type and timing of out of hours tests. The most common tests to take place outside routine hours in South Thames in March 1999 were full blood counts $(54.7 \%)$ and clotting screens $(20.5 \%)$, followed by cross matches $(6.4 \%)$ and blood groups $(4.8 \%)$. There were differences between centres in the number of different types of tests performed out of hours (table 2). The increases between 1996 and 1999 varied from $42 \%$ for cross matches and $67 \%$ for full blood counts, to $118 \%$ and $126 \%$ for clotting screens and blood groups, respectively.

The impact on workload of different out of hours service provision was examined to determine whether offering a greater level of service resulted in greater uptake. The method of providing out of hours services did not seem to affect total numbers of out of hours tests or out of hours tests/acute bed (table 3).

In March 1999, $18.3 \%$ of total out of hours tests (11 725) took place between midnight and 08.00 , ranging from $3.5 \%$ (12 tests) to $44 \%$ (1471 tests). The least number of tests were undertaken after midnight in the two centres with Whitley Council on call and the most in the two centres with a full shift system.

COST OF OUT OF HOURS SERVICES

Each centre was asked to provide information on the direct costs of providing out of hours services. These included staff payment, travel costs, telephone costs, and staff time off in lieu. Costs such as electricity and test materials were not included in the calculations.

The relative costs of providing haematology laboratory out of hours services in South Thames vary depending on the method of analysis. Costs were examined in three ways: cost/hour, cost/test, and cost/acute bed.

The cost/hour of running an out of hours service ranged from $£ 4.41$ to $£ 42.63$. The two hospitals using Whitley Council payment provided out of hours services at the cheapest hourly rate (almost half that of the next nearest centre). These two hospitals have few acute beds and low out of hours workload.

The cost/test of out of hours workload ranged from $£ 0.72$ to $£ 6.52$. Full shift systems provide the second and fourth least expensive out of hours service. The three centres with the

Table 3 Out of hours (OOH) tests by service provision

\begin{tabular}{llll}
\hline $\begin{array}{l}\text { Method of OOH service provision } \\
\text { (number of centres) }\end{array}$ & $\begin{array}{l}\text { Total out of hours tests } \\
\text { (March 1999) }\end{array}$ & $\begin{array}{l}\text { Range of out of } \\
\text { hours tests/centre }\end{array}$ & $\begin{array}{l}\text { Range of tests/ } \\
\text { acute bed/centre }\end{array}$ \\
\hline Fixed sessional payments (15 centres) & 45315 & $930-8181$ & $2.3-8.7$ \\
Full shifts (2 centres) & 10326 & $3396-6930$ & $5.9-7.1$ \\
Partial shifts (3 centres) & 14453 & $1275-11464$ & $2.5-16.9$ \\
Whitley Council payments (2 centres) & 1640 & $378-1262$ & $4.7-6.3$ \\
All methods (22 centres) & 71734 & $378-11464$ & $2.3-16.9$ \\
\hline
\end{tabular}


lowest cost/test are among the six centres performing the greatest number of out of hours tests.

The cost/acute bed of providing out of hours services ranged from $£ 11.33$ to $£ 28.81$ in March 1999. The two full shift systems offered the lowest cost/acute bed. The three partial shift systems cost less than the regional average. Similarities were noted between centres providing cost effective services when examining cost/test and cost/acute bed. The same four centres feature as the lowest costing when analysed by test and by bed.

STAFF TIME OFF IN LIEU

The monthly cost of time off in lieu for on call staff varied across the South Thames region from $£ 0.00$ to $£ 3138.75$. The monthly cost/ acute bed ranged from $£ 0.00$ to $£ 8.86$. Actual time off in lieu ranged from none to two days for each on call shift worked.

\section{Conclusions}

The most appropriate way of apportioning costs for out of hours work to enable valid comparative analysis is by calculating cost/ acute bed. This method takes into account hospital size.

Despite adopting common definitions of tests and requests since the 1996 audit there is still a pronounced difference between centres in the number of tests performed/acute bed. However, the audit did not examine the proportion of general practitioner work carried out by the laboratories and this may account for some of the differences.

An interesting finding from the audit is the increase in acute medical beds in the former South Thames region between 1996 and 1999. This may be a result of the population increase in the South East.

The variation and increase in out of hours tests/acute bed is not related to the way in which out of hours services are provided. Therefore, the increase between 1996 and 1999 is more likely to be the result of changes in medical practice. The moves by clinicians to provide a 24 hour service for patients in acute admissions wards, theatres, and trauma centres and to reduce the length of stay is driving this. Analysis by out of hours tests/acute bed and by out of hours tests/admission resulted in similar variations between centres, and it appears that either method of analysis gives a similar correlation, in spite of increased patient throughput.

There are some important differences between centres in the numbers of different types of tests performed out of hours, which are not related to the numbers of acute beds. In general, hospitals with full and partial shifts performed more out of hours tests in all categories but there were some interesting variations. In one hospital, $33 \%$ of its out of hours work consisted of blood grouping between 24.00 and 08.00 . The tests categorised as "other" (that is, not full blood counts, blood groups, cross matches, or clotting screens) varied from $0 \%$ to $33.9 \%$ of the total out of hours tests. It is possible that some laboratories have made a decision to perform some routine work out of hours, but it might be useful for individual laboratories to examine this in more detail to determine whether this is cost effective and whether there is an indication for changing their practice.

The audit results suggest that full and partial shift systems are the most cost effective way of providing an out of hours service when related to the numbers of acute beds. This probably results from economies of scale and reflects the fact that these methods of provision only become possible in large laboratories with a high workload. Similarly, in our study the Whitley Council payments appear to provide the cheapest method of out of hours provision in small laboratories with a low workload. However, this is not necessarily a like-for-like comparison with shift systems. In shift systems, some of the overhead costs will be part of the hourly cost, whereas for Whitley these overhead costs are only applied to the routine working period. The type of out of hours service provision should be chosen taking workload and local circumstances into account, and there is no single model that suits all situations.

The cost and organisational problems associated with time off in lieu for staff undertaking out of hours work will become more acute with the implementation of the recent European directive, which gives employees the right to refuse to work more than an average of 48 hours/week, ${ }^{45}$ and is likely to result in considerable increases in the cost of providing out of hours pathology services. There are also health and safety implications associated with staff working long shifts with little sleep. Single departmental working for all methods of out of hours provision may have to be replaced by multidisciplinary working to meet the legal requirements. Alternatively, if the demand for out of hours tests continues to increase it is possible that more than one member of staff will be required to cope with the out of hours workload for at least part of the night shift. In many laboratories the intensity of work is as much of a problem as the number of hours worked.

We thank the South Thames haematology specialist subcommittee.

1 Shirley J. Changing working patterns. In: Galloway M, ed. Clinical director of pathology: tackling the role. Oxford: Radcliffe Medical Press, 1999:149-62.

2 Phekoo K, Shirley J. Haematology on-call workload-audit report. 1997.

3 Clinical Benchmarking Company. Pathology feedback report 1997 haematology. London: Clinical Benchmarking Company, 1998.

4 The Home Office Partnership. Working time directive-a catalyst for radical change? Flexibility - the interactive forum of new ways of working, Website 1999. News, page 1. (www.flexibility.co.uk)

5 European foundation for the improvement of living and working conditions. Briefing paper 98/18. The working time directive 1998. 